\title{
Co-operation between Europe and some Southern and Eastern Mediterranean Countries on the use of ICT in Education: constrains and opportunities learnt from several European projects
}

Dumont B. ${ }^{1}$

\section{N F O}

Received 16 Sept. 2010

Accepted 10 Dec. 2010

Available on-line 3 Apr. 2013

Responsible Editor: A. B.

Sideridis

\section{Keywords:}

ICT in education, intercultural education, European project, co-operation, mediterranean countries.

\begin{abstract}
A B S T R A C T
Based on previous experience in Southern Europe and Middle-East, potentiality and constraints in collaborative projects are presented. More specifically, a number of EC funded ICT projects, undertaking by countries of these regions and implemented the last seven years, are presented in brief. By the introduction of quality issues and carefully examining a number of constraints and difficulties appeared during the development of these projects, we propose specific recommendations for successful co-operation, especially at a moment of deep and strong changes in these regions.
\end{abstract}

\section{Introduction - Some projects as bases for concrete examples}

Considerations presented in this paper are based on experience gained from several projects. They are described briefly to facilitate the background of the reflection developed in the following paragraphs.

\subsection{META-ETE $[2005-2009]^{2}$}

This project was funded by the EC, under the Agency European Training Foundation ${ }^{3}$ (ETF) to support Mediterranean institutions in the design of relevant technical and vocational education and training policies that can contribute to promote employment through a regional approach. The project involved: Algeria, Tunisia, Morocco, Lebanon, Egypt, Jordan, Palestine, Israel, Syria, and Turkey.

The component focused on e-learning. It offered an online course in English and French, on Moodle, plus meetings, focusing on methodology to develop and deliver e-learning with practical activities on ICT and tourism.

\subsection{Fostering Human Rights through Intercultural Education in South Caucasus and Ukraine [2006 - 2009]}

This project was jointly funded by the European Commission and the Council of Europe (CoE) ${ }^{4}$ It has been implemented by the CoE in co-operation with the educational authorities of Armenia, Azerbaijan, Georgia and Ukraine. It aimed to promote awareness of intercultural education (Rey-von Allmen, 2010) and support drawing-up educational policy guidelines addressing cultural and religious diversity at all levels of education. It also aimed to help improve practice in this field by developing educational materials and by disseminating and translating existing materials from CoE into the languages of the participating countries.

\footnotetext{
${ }^{1}$ DUMONT, Bernard

Consultant (France), http://bdumont.consultant.free.fr/

bdumont.consultant@gmail.com

${ }^{2}$ www.meda-ete.net

${ }^{3}$ www.etf.europa.eu

${ }^{4}$ www.coe.int
} 
The activities included country assessments to identify main issues, needs, existing resources, opportunities and the key stakeholders to be involved. Meetings were organised at regional level, as well as awareness-raising conferences and workshops in each country, involving teachers, teacher trainers and education specialists. The development of co-operation and exchanges at regional level was also foreseen and, for this purpose, a virtual collaboration space has been made available on Moodle.

\section{3. e-Quality [2003 - 2006 $]^{5}$}

Gathering 5 European Countries (Finland, France, Poland, Spain, and Switzerland), representing 6 institutions, the e-Quality project was carried out with the support of the European Community within the Action MINERVA of the Programme SOCRATES. The project focused on the "teaching and learning" quality dimension in order to be a pragmatic tool that helps improving the day by day work of the e-learning stakeholders in higher education institutions.

The main outcomes of the project were the production of methodologies, tools and training packages, the training of teams of actors involved in e-learning, one in each participating country, the evaluation of the applicability of these methods and tools in real life, and a databank of « good practices ».

\subsection{Repositories: COSMOS $[2007-2009]^{6}$, Organic.Edunet $[2007-2010]^{7}$}

These 2 projects, funded under the eContentPlus Programme of the European Commission, are similar in terms of use of ICT for education. They aim at providing teachers and learners with multilingual pedagogical digital resources and scenarios for 2 topics: astronomy for COSMOS, organic agriculture and agroecology for Organic.Edunet.

The main purpose of the COSMOS project was to create an experimental laboratory for students and teachers in order to improve science instruction by expanding the resources for teaching and learning in schools and universities. The project involved 15 institutions from Austria, Bulgaria, Cyprus, France, Germany, Finland, Greece and Sweden. The COSMOS project deployed a Web Repository of educational content using multilingual vocabularies that facilitates end-users' search, retrieval, access and use of both scientific and educational resources.

Organic.Edunet is a multilingual federation of learning repositories with quality content for the awareness and education of European youth. It includes 16 partners from 10 countries (Austria, Estonia, Germany, Greece, Hungary, Norway, Romania, Spain, Sweden, and UK). It aims to facilitate access, usage and exploitation of digital educational content related to Organic Agriculture (OA) and Agroecology. It also deploys a multilingual online environment (the Organic.Edunet Web portal) that facilitates end-users' search, retrieval, access and use of the content in the learning repositories.

\section{Potentiality of co-operative projects}

Co-operative projects, like those mentioned above, offer good opportunities not only to produce together new knowledge or resources, but also to share experience, know-how, existing material etc.

\subsection{To re-use existing (raw) material}

2 projects based on repository are good examples of development of tools making easier the re-use of existing pedagogical resources and scenarios from several countries. Doing so, teachers and trainers can benefit from other colleagues' work, saving time and having some guarantee on this material. In the participating countries in the CoE project, documentations (articles, books...) and access to it is difficult for teachers and students, even at university level and in teacher training centers. So in this project an effort was done to give access to documents from $\mathrm{CoE}$ in a digital form.

\footnotetext{
${ }^{5}$ www.e-quality-eu.org

${ }^{6}$ www.cosmos-project.eu

${ }^{7}$ www.organic-edunet.eu
} 


\subsection{To take advantage of other people's experience}

Another advantage of the co-operative projects is to give an opportunity to people coming from different educational contexts to meet regularly for a few years, to know each other, to visit places where colleagues live and work, to see teaching methods in situ, to compare and discuss situations in different countries. Travel is part of the learning experience for participants, and it is a quite important aspect of these projects, even from the EC point of view. Beside formal meetings, participants can see how people live, work and behave, in schools and outside. Cultural issues are very important in postcommunist countries. Historic conditions shaped a strong national identity, going along with problems linked with ethnic relations, migration and diasporas; sociopolitical tensions are accompanying the transformation, cultural hybridization, globalization, and for some of these countries, the entrance in the European Union. Participation in transnational cooperation and programs, especially with Western European countries plays a strategic role to support such cultural and organizational changes (Bleszynska, 2010). Cultural issues, even if they are not as strong as in the post-communist countries, are to be taken on board also in Western European countries. For instance, it has been a very tricky aspect of the e-Quality project to define quality indicators as, for example, the responsiveness of tutors because the role and the obligations of teachers were quite different between French and Finnish universities. What seemed natural in Finland appeared as quite demanding in France.

Working together in projects, coming from countries with such different cultural and historic backgrounds, is stimulating and demanding if all participants strongly wish to understand each other and share experience, results and resources.

\subsection{To get common experience and to produce material together}

A project is not limited to share existing products but mainly it aims at co-producing new methods, tools, resources that can be used in the participating countries, and after the end of the project, in other countries. Usually, competences are not the same in the different teams but they are completing each other. Each participant brings something to the consortium and learns something. The 2 projects on repositories are examples of co-operation where teachers can upload their material, download material from other teachers, can give feedback after trying them in their classrooms, and improve existing resources.

\subsection{To take advantage of Moodle or other open source tools (for instance for rare languages)}

As we said above, the CoE project made possible for participants an access to digital versions of documents as articles, books and other official papers from the Council, plus other resources not protected by copyright. Mooddle was used to support this access to data and also to allow communication between participants. Moodle has 2 main advantages in this kind of project with limited funding and countries not able to spend a lot of money on their own. As an open source platform it does not need to be bought or to pay some fees to use it. On top of it, there is some localization for interface in rare languages as Georgian or Armenian, that doesn't exist in commercial products.

Moodle was used within the MEDA-ETE project as a Learning and Content Management System (LCMS) for the e-learning courses offered by the ETF agency. It has been also used by some of the participating national institutions that wanted to deliver their own courses, as in Jordan for instance, or simply to practice and test some learning material developed during the project. Interfaces were used in French, English and Arabic.

\section{Constraints to take on board}

Working in international projects, involving countries from Eastern and Southern Europe, or from the Mediterranean area, brings some constraints to take into account from the beginning. 


\subsection{Technical environment}

As soon as ICT are part of the project, either as the core or as a support, the technical issues have to be addressed, especially:

- Configuration of computers: one can find old versions of OS and software, no USB entrance.

- Number of students per computer: this number is important to design pedagogical activities; the "official" number maybe different of the real one, depending of out of order computers in the institution.

- Internet access: problems can be internal to the institution (rules, authorization, forbidden websites) but also external, due to the quality of the Internet provider (speed, regularity of Internet connection).

- Availability of electricity: in some countries electricity can be off without warning or available only at some periods of the day or of the week.

\subsection{Political, cultural and linguistic context}

In these countries it is fundamental to forget the Western representation of administration, hierarchy, decision making process, to consider the real political, cultural and linguistic environment.

Some issues may be addressed - preferably during the writing of the proposal - to take into account the context in which your partners will work during the project. It is important to be aware of the political context, to know the role of the hierarchy in the decision making process about the project progress. Some forms of censorship can limit the persons involved in the project to express their own position or to take initiatives about content. In some cases, participants may have no way to manage the budget or even to decide who is going to travel to participate in a project meeting.

Linguistic situation is important issue to be aware of. One needs to go beyond too simple vision and to always take on board the link between language and culture. For instance, in post-communist countries, most of older staff in universities knows Russian better than English, but they are reluctant to express themselves in Russian in public, and they prefer to speak their national language. Nevertheless, when they meet with colleagues from other countries from the area, Russian stays the only language for communication. It is a mistake to believe that English can be used for collaborative activities, on forum for instance. Younger researchers and teachers are more at ease with English. So, the project could be designed differently, depending of the target group. In Lebanon, French, instead of Arabic, is mainly used at university and secondary school levels to teach sciences. So pedagogical resources in Arabic are not useful in this country at these educational levels. The mix between Arabic and French in Education is a very complicated situation also in North-Africa. On top of it, "pure" Arabic is not the inhabitants' spoken language; they speak a vernacular one, different from a country to another. A specific budget for translation is needed but enough money is needed to assure a good quality translation, to avoid difficulties of reading and understanding.

International co-operation presents different situations depending on whether the co-operation is with Western European countries, or with countries from the same region. This is obvious when there is a conflicting situation between countries (Armenia / Azerbaijan, Lebanon / Israel), but not only. Cultural differences and political constraints may explain some difficulties for such co-operation. For instance, in Israel, some governmental funding is available for projects with Palestine or Egypt, but it is difficult to succeed in building such projects. Cultural barriers seem to make uneasy cooperation in ICT between well advanced organizations in a small country like Jordan with developing ones in a very big country as Egypt. Nevertheless, the (r)evolutions going on in several countries of the region will certainly bring a lot of cultural and organizational changes, with a strong impact on international co-operation.

\section{Quality issues}

All proposals submitted for funding from EC are including a work package, or at least a part of the description of the management, on Quality Assurance. It is understandable as funding is public money. The issue of managing quality during the project is directly linked to the above considerations as it is fundamental to anticipate risks and dysfunctions (Dumont and Sangrá, 2006). 
There are several aspects of Quality in a project using ICT.

The Quality of resources concerns resources offered to partners as well as resources developed during the project by the consortium. Quality of translation has been already mentioned, but for pedagogical resources, localization is often needed. The quality of such adaptation is a way to prevent the risk of a weak usability of the resources within the educational context of these countries.

The Quality of the technical environment includes the strengths and the weaknesses of the equipment of the local partners but also of the national context, especially service offered by Internet and electricity providers. The project can be designed on the existing situation with or without possible improvement, depending of the budget.

As it is difficult to assure a constant quality of the technical devices during all the time of the project, the Quality of human support is fundamental to keep high the motivation of the participants, especially the trainees, and to lower the risk of drop out. The design of the pedagogical activities should include human support as part of the whole system.

The method called "continuous improvement”, issued from the norms ISO $^{8}$ about Quality Management, can be a useful tool for the project management. It is based on a process able to quickly detect dysfunctions, get feedbacks from users and other stakeholders, analyze and solve problems, and then propose some improvement to avoid these problems to occur again.

Another consideration, from norms ISO, concerns the top management: it MUST be committed to implement quality step in an organization. It is also the case in these countries where hierarchy and administration are very strong in the decision making process. To achieve the foreseen goals, in time and with the expected quality of the outcomes, top management must be strongly supporting the project, and all the staff who are going to work in it.

\section{Recommendations for success stories}

Here are some recommendations; of course they are not limited to Caucasus, North-Africa or Middle-East regions.

- One must be aware of cultural and technical differences between participating countries to minimize their impact on the project;

- One does not trust the «European idealistically simple » views about some countries or regions. Recent events prove, for instance, that people from Arabic countries can take courageous initiatives to change what we could imagine lasting forever.

- The design of the projects must take into account the specificity of (end) users, and leave them some « space » to adapt the product to local needs.

- Work team should be put ahead instead of individual contributions.

- The project should include training for participants (staff, trainers, etc.) in the global package.

- The budget should include enough money for localization of the pedagogical resources, not only translation.

- Avoid humor, as it is difficult to be sure that something funny in one country is not an insult in another.

\section{Sure, it's worth it!}

Even if there are a lot of difficulties and constraints to participate in such projects, it's worth it, and people from these developing countries deserve to be supported. Having presented some examples of such difficulties encountered in the projects, it is time to show also examples of success. From the project with South Caucasus and Ukraine, a handbook for teachers, with pedagogical activities proposed by teachers from the 4 countries, has been published by the Council of Europe (WolffJontofsohn, 2010). From the MEDA-ETE project, even if regional co-operation has not been effective as expected, some results are highly positive, for instance: the improvement of the quality of elearning material in partners from Jordan, Israel and Lebanon, the collaboration between public and

\footnotetext{
${ }^{8}$ www.iso.org
} 
private organizations to develop e-learning in Egypt and in Morocco. Several experiences, as the work done between Israeli and Palestinian teachers who developed a common history textbook, proved that even in this part of the Mediterranean Sea co-operation is possible and productive (Steinberg and Baron, 2009).

What is going on in North-Africa and Middle-East, with deep changes in politics and daily life, is making even stronger the need to support the development of training in all sectors of education and by all means, including ICT and e-learning. It is clear that EC will soon decide to actively accompany these changes and to promote multilateral projects.

Projects promoting and supporting the use of ICT in developing countries, participate in reducing the digital gap within societies and inculcating media and computing literacy in schools. And doing so, co-operative projects support the development of a more robust critical multiculturalism among young generations (Carr and Porfilio, 2009).

\section{References}

Bleszynska, K. M. 2010. Chapter 5: Intercultural education in post-communist countries. In Intercultural and Multicultural Education - Enhancing Global Interconnectedness, 69-82. Carl A. Grant, Agostino Portera, ed.: Routledge.

Carr P. R., B. J. Porfilio. 2009. Computers, the media and multicultural education: seeking engagement and political literacy. Journal of Intercultural Studies 20(2): 91-107.

Dumont B., A. Sangrá 2006. Organisational and cultural similarities and differences in implementing quality in e-learning in Europe's higher education. In Handbook in Quality and Standardisation in E-learning. Ulf-Daniel Ehlers and Jan Martin Pawlowski, Ed., Springer.

Gobbo, F., G., Jacobs and I. Pescarmona. 2010. Cooperative learning and intercultural education in multicultural societies: critical reflections. In Intercultural education 21(3): 195-203.

Gundara J. S. 2010. Chapter 19: Citizenship and intercultural education in an international and comparative context. In Intercultural and Multicultural Education - Enhancing Global Interconnectedness.Carl A. Grant, Agostino Portera, ed.: Routledge

Rey-von Allmen M. 2010. Chapter 3: The Intercultural perspective and its development through cooperation with the Council of Europe. In Intercultural and Multicultural Education - Enhancing Global Interconnectedness. Carl A. Grant, Agostino Portera, ed.: Routledge.

Steinberg, S. and D. Bar-on. 2009. The other side of the story: Israeli and Palestinian teachers write a history textbook together. Harvard Educational Review 79(1): 104-112.

Wolff-Jontofsohn, U. 2010. Living in diversity: Lesson plans for secondary schools. The Council of Europe, Directorate of education and languages. Council of Europe Publishing. 